\title{
The Effect of Stevia Rebaudiana on Serum Omentin and Visfatin Level in STZ-Induced Diabetic Rats
}

Samad Akbarzadeh ${ }^{1}$, Fatemeh Eskandari ${ }^{2}$, Hadis Tangestani ${ }^{2}$, Somaieh Tangerami Bagherinejad ${ }^{2}$, Afshar Bargahi ${ }^{1}$, Parviz Bazzi ${ }^{3}$, Adel Daneshi ${ }^{4}$, Azam Sahrapoor ${ }^{2}$, William J. O'Connor ${ }^{6}$, \& Ali Reza Rahbar ${ }^{5}$

${ }^{I}$ Department of Biochemistry, School of Medicine, Bushehr University of Medical Sciences, Bushehr, Iran, ${ }^{2}$ The Student's Committee Research, School of Medicine, Bushehr University of Medical Sciences, Bushehr, Iran, ${ }^{3}$ Department of Anatomy, School of Medicine, Bushehr University of Medical Sciences, Bushehr, Iran, ${ }^{4}$ The Persian Gulf Marine Biotechnology Research Center, Bushehr University of Medical Sciences, Bushehr, Iran, ${ }^{5}$ Department of Nutrition, The Persian Gulf Tropical Medicine Research Center, Bushehr University of Medical Sciences, Bushehr, Iran, ${ }^{6}$ The UCD School of Mechanical \& Materials Engineering, University College Dublin, Dublin, Ireland

\begin{abstract}
Recently the role of adipocytokines in relationship to incidence of diabetes has been demonstrated. One of the medicinal plants that are used in the treatment of diabetes is stevia. This study investigates the effect of stevia on serum omentin and visfatin levels as novel adipocytokines in diabetic induced rats to find potential mechanisms for the anti hyperglycemic effect of stevia. Forty male wistar rats weighing 180-250 $\mathrm{g}$ were induced with diabetes by intraperitoneal injection of streptozotocin (STZ). The animals were divided into 5 groups of 8 . Rats in group 1 (non-diabetic control) and group 2 (diabetic control) were treated with distilled water, and the rats in the treated groups, group 3 (T250), group 4 (T500), and group 5 (T750) were treated with stevia, gavaged every day at 9 a.m. in doses of 250,500 , and $750 \mathrm{mg} / \mathrm{kg}$, respectively. At the end of the study significant reductions in fasting blood sugar (FBS), the homeostasis model assessment insulin resistance (HOMA-IR), triglyceride (TG), alkaline phosphatase (ALP), and Omentin level were found in groups 3 and 4 in comparison with group 2. Pancreatic histopathology slides demonstrated that stevia extract did not induce any increase in the number of $\beta$-cells. The conclusion is that prescription of stevia in the doses of 250 and $500 \mathrm{mg} / \mathrm{kg} / \mathrm{d}$ decreases the omentin level indirectly via activating insulin sensitivity and lowering blood glucose in STZ-induced diabetic rats.
\end{abstract}

KEYWORDS. Diabetes, omentin, stevia, visfatin 


\section{INTRODUCTION}

The number of diabetic patients has been increasing rapidly worldwide, and prevention of diabetes advancement is a major issue in the 21th century (Zimmet, Alberti, \& Shaw, 2001). The World Health Organization (WHO) estimates that more than 180 million people worldwide have diabetes and this number will likely double by 2030 (WHO, 2000). In diabetic patients, chronic increase in blood glucose concentration leads to insulin resistance and induces complications characteristic of diabetes, such as coronary heart disease, hypertension, renal failure, serum lipid distortion, etc. For the treatment of diabetes, especially in eastern countries, in addition to the restriction of energy and the promotion of exercise, the use of medicinal plants has played an important role. These novel compounds are used by traditional herbalist for the management of diabetes in several regions of Iran (Fallah-Hoseini, Fakhrzadeh, Larijani, \& Shikhsamani, 2006).

One of the medicinal plants widely used as an alternative medicine in the treatment the hyperglycemia in diabetes is stevia. Stevia rebaudiana that grows in South America does not contain useable carbohydrates for humans. It contains Stevioside, rebaudiosides A, B, C, D, E, and F, dulcoside A, and steviolbioside. Natural sweet-tasting glycosides, isolated from the herb, are 200-350 times sweeter than sucrose and have been used as a natural sweetener in Brazil and Japan for decades (Soejarto, Kinghorn, \& Farnsworth, 1982; Lailerd, Saengsirisuwan, Sloniger, Toskulkao, \& Henriksen, 2004; Chen et al., 2005). In addition, the extract of stevia has shown the ability to decrease the blood glucose level in diabetic patients (Kujur et al., 2010; Jeppesen, Gregersen, Poulsen, \& Hermansen, 2000; Chen et al., 2005). So far various mechanisms have been reported to be active in the hypoglycemic property of stevia, such as enhancement of insulin secretion, activation of glucose utilization, counteracting the glucotoxicity in $\beta$-cells and suppressing the glucagon secretion by $\alpha$-cell of pancreas (Jeppesen et al., 2000; Chen et al., 2005, Chen et al., 2007, Shibata et al., 1995).

Recently the role of adipocyte derived cytokine in the incidence of diabetes has been demonstrated (Bulcao, Ferreira, Giuffrida, \& Ribeiro-Filho, 2006; Yang et al., 2006). Visfatin and omentin are two novel adipocyteokines that are involved in insulin signal transduction (Yang et al., 2006), glucose homeostasis (Chandran, Phillips, Ciaraldi, \& Henry, 2003) and insulin-mimetic effects (Fukuhara et al., 2005). There are some clinical trials that studied the relationship between glucose lowering agents (metformin and resiglitasone) and adipocytokines (Esteghamati et al., 2013) but to the best of our knowledge there is no published report to show the effect of stevia consumption, as a novel glucose lowering remedy (FDA approved), on serum adipocytokines concentration in an animal or human model study. Therefore we undertook this research to investigate the impact of stevia on serum omentin and visfatin levels in diabetic induced rats, in order to find other potential mechanisms involved in the hypoglycemic property of stevia. Furthermore the dose effectiveness dependency of stevia on morphology of the liver and pancreas as well as lipid and glycemic parameters was evaluated.

\section{MATERIAL AND METHODS}

Forty specific pathogen-free male wistar rats weighing 180-250 g were provided from the Medical Center Animal Research facility at Esfahan University of 
medical sciences. They were housed in micro-filter-top cages at Bushehr University of medical sciences animal house. The animals were allowed to acclimatize for 2 weeks at $22 \pm 3^{\circ} \mathrm{C}$ with a 12:12-hr light:dark cycle and $60-65 \%$ humidity, provided with rodent chow and water ad libitum. All experimental protocols were followed under the approval from the Animal Care and Use Committee for Animal Investigations. The experimental model was conducted in a manner consistent with the relevant ethical guidelines for animal research. The animals were randomly divided into 5 groups of 8 members each. After fasting for $12 \mathrm{~h}$, the experimental diabetes was induced by intraperitoneal injection of a single dose of $60 \mathrm{mg} / \mathrm{kg}$ of streptozotocin (STZ) (Alexis Biochemical, Lot-L24553) to the rats in all the groups except one which was assigned to be the non-diabetic control group. After 5 days of the STZ injection, blood samples were taken from the tail of the subjects and the glucose level was measured by glucometer (Bionime Rightest GM 300, Switzerland). Animals with a blood glucose value of $>300 \mathrm{mg} / \mathrm{dL}$ were assumed to be diabetics (Heidarian \& Soofiniya, 2011) and the others were excluded.

Stevia was supplied from the north of Iran. Sample specimens were authenticated by the herbarium of the research center of Agriculture and Natural Resources of Bushehr Province, Iran. The voucher was deposited in the Herbarium of Bushehr University of Medical Sciences. The aqueous extract of stevia plant was obtained by boiling aerial parts for $30 \mathrm{~min}$ in distilled water at a ratio of 1:100 w/v, and incubated overnight at $40^{\circ} \mathrm{C}$ with slow shaking on an orbital shaker (Stuart Scientific Orbital Shaker, UK). The hydrosoluble part was centrifuged $(6000 \mathrm{~g}, 10 \mathrm{~min})$ and insoluble precipitate was discarded. The supernatant was filtered by Whatman No. 1 paper. The filtrate was concentrated under reduced pressure at $40^{\circ} \mathrm{C}$ using a rotary evaporator (Laborota 4000, Heildolph, Germany) and finally freeze-dried to get the stevia extract. The resulting sample was powdered and plastic sealed for future use.

Rats in group 1 [non-diabetic control group (N-DC)] and group 2 [diabetic control group (DC)] were treated with distilled water, and the rats in group 3 (T250), group 4 (T500), and group 5 (T750) were treated with stevia, gavaged every day at 9 a.m. in corresponding doses of 250,500 , and $750 \mathrm{mg} / \mathrm{kg}$, respectively. The rats in all groups continued to consume their usual diet while taking the stevia or distilled water. The rat diet included brown rice, oats, wheat, soy, and fish meal, Calcium Carbonate, Yeast Culture Dehydrated, Flax Seed Meal (Linseed), Inulin, Monocalcium Phosphate, Soy Oil and needed vitamins and minerals (Table 1).

At the end of the 30th day of the study, after $12 \mathrm{hr}$ nocturnal fasting, the rats were given a lethal overdose of isoflorane by inhalation. Subsequently the blood

TABLE 1. Analysis of the Nutrients Contained in Rat Diet

\begin{tabular}{lr}
\hline Crude carbohydrate & $58.00 \%$ \\
Crude protein & $15.00 \%$ \\
Crude fat & $4.00 \%$ \\
Crude fiber & $7.00 \%$ \\
Moisture & $10.00 \%$ \\
Calcium & $1.20 \%$ \\
Phosphorous & $0.80 \%$ \\
\hline
\end{tabular}

Premium Ingredients: Brown Rice, Oats and Wheat, Soy and Fish Meal. 
samples were taken from the heart into a syringe and placed on ice; all blood samples were promptly centrifuged at $3000 \mathrm{~g}$ for $5 \mathrm{~min}$ at $4^{\circ} \mathrm{C}$, the serum was separated, and it was kept at $-80^{\circ} \mathrm{C}$ for further analysis. Analyses were carried out at the laboratory of the Persian Gulf Tropical Medicine Research Center on the day of the blood collection. Serum glucose, triglycerides (TGs), total cholesterol, and HDL cholesterol were determined using the enzymatic method (Pars Azemon Co, Iran) by an auto analyzer, selectra-2 (vital science, spankeren, Netherlands). Insulin was measured using ELISA (Alpco Insulin ELISA kit). Homeostasis model assessment insulin resistance (HOMA.IR) of fasting blood sugar (FBS) and homeostasis model assessment insulin-B cells (HOMA-B) were calculated by the following formulae (Matthews et al., 1985):

$$
\begin{aligned}
\text { HOMA }-\mathrm{IR} & =\frac{\operatorname{Insulin}\left(\frac{\mu \mathrm{IU}}{\mathrm{ml}}\right) \times \mathrm{FBS}\left(\frac{\mathrm{mmol}}{\mathrm{ml}}\right)}{22.5} \\
\mathrm{HOMA}-\mathrm{B} & =\frac{20 \times \operatorname{Insulin}\left(\frac{\mu \mathrm{IU}}{\mathrm{ml}}\right)}{\operatorname{FBS}\left(\frac{\mathrm{mmol}}{\mathrm{ml}}\right)-3.5}
\end{aligned}
$$

Serum omentin concentrations were measured using rat omentin ELISA kit [ELISA kit, Cat. No: CK-E11073. China]. The detection limit of the assay and sensitivity were $2-600 \mathrm{ng} / \mathrm{L}$, and $1.12 \mathrm{ng} / \mathrm{L}$ properly. The intra and inter-assay coefficients of variance were less than $10 \%$ and $20 \%$, respectively. To detect visfatin in the serum samples, a commercially available (Cat. No.V0523EK) enzyme-linked immunosorbent assay kit (Adipo-Gen, Seoul, Korea) was used following the manufacturer's instructions. The assay sensitivity for visfatin was $0.10 \mathrm{ng} / \mathrm{mL}$; the intra and inter-assay coefficients of variance were $3.8-5.5 \%$ and $6.4-9.5 \%$, respectively.

To evaluate the histopathology changes in the pancreatic $\beta$-cells and in the liver of STZ-induced diabetic rats, pancreatic and liver biopsies were taken on the 30th day of the study. The samples were fixed and dehydrated by formaldehyde and alcohol properly. Subsequently the fixed samples were molded and embedded by paraffin and finally they were cut in 3-micron thickness and stained ( $\mathrm{H}$ and E staining) for evaluation by light microscopy. Light and electron micrographs of samples which obtained through light microscopy were carefully studied and evaluated for morphological changes.

\section{Statistical Analysis}

The distribution of variables was studied using probability plots and the ShapiroWilks test. Due to the $\chi^{2}$ distribution of the variables, nonparametric tests were used to analyze the data. The differences after intervention between groups in omentin, visfatin, lipidemic, and glycemic parameters were analyzed by Kruskal-Wallis. Mann-Whitney $U$ was used wherever there was a main effect in order to compare variables between each group separately. A value of $p<.05$ was accepted as significant. Statistical analysis was performed using the SPSS 15 statistical software package (SPSS Inc., Chicago, IL). 


\begin{tabular}{|c|c|c|c|c|c|}
\hline $\begin{array}{l}\text { Groups } \\
\text { Tissues }\end{array}$ & N-DC & DC & $\mathrm{T}_{250}$ & $\mathrm{~T}_{500}$ & $\mathrm{~T}_{750}$ \\
\hline \multicolumn{6}{|l|}{ Liver } \\
\hline Pancreas & & & & & \\
\hline & & & & & \\
\hline
\end{tabular}

FIGURE 1. Photomicrographs of liver and pancreatic images of STZ- induced diabetic rats. Group 1 [Control: the non-diabetic control group], group 2 [Diabet, the diabetic control group], group 3 (fed $250 \mathrm{mg} / \mathrm{d}$ stevia], group 4 [fed $500 \mathrm{mg} / \mathrm{d}$ stevia], group 5 [fed $750 \mathrm{mg} / \mathrm{d}$ stevia] ( $\mathrm{H}$ and $\mathrm{E}$ staining, $\times \mathbf{4 0 0}$ magnification). Stevie extract administration did not induce any increase in the number of $\beta$-cells of pancreatic islets in all of the treated groups. In addition no sign of liver tissue deterioration was seen following stevia prescription.

\section{RESULTS}

After STZ injection the FBS in the animals in the study were $318.00 \pm 131.78$ which showed that all the rats were induced with diabetes. The FBS and weight of the diabetic rats confirmed that the groups were well matched for all entry criteria (data not shown) and that there were no significant differences between the groups.

After 30 days of stevia consumption, a significant reduction in FBS in group 3 (T250) $(p=.03)$, as well as in group 4 (T500) $(p=.03)$ was seen in comparison with group 2 (DC). The HOMA-IR also decreased in group 3 (T250) $(p=.04)$ and in group 4 (T500) ( $p=.01)$ sequel stevia prescription. A significant decrease in the TG level was observed in group 3 (T250) $(p=.02)$ and in group 4 (T500) $(p=.02)$ in comparison with group 2 (DC) at the end of the study. The decline in omentin was also significant in group 3 (T250) $(p=.01)$ and in group 4 (T500) $(p=.01)$ compared to group 2 (DC). The ALP level at the end of the study decreased in group 3 (T250) $(p=.010)$ as well as in group 4 (T500) $(p=.01)$ after intervention. The stevia supplementation of $750 \mathrm{mg} / \mathrm{kg} / \mathrm{d}$ showed no significant changes in any biochemical parameters between the groups (Table 2).

The difference in the fasting insulin concentrations, HOMA-B, visfatin, cholesterol, and HDL-C were not significant between the treated groups and group 1 (N-DC) and 2 (DC).

The pancreatic and hepatic histopathology slides of all the groups were prepared on the 30th day of study. As shown in Figure 1 the stevia extract did not induce any increase in the number of $\beta$-cells of pancreatic islets in any of the treated groups. In addition no sign of liver tissue deterioration was seen in histopathology slides after the stevia treatment in the diabetic rats.

\section{DISCUSSION}

Omentin as a novel adipocytokine has been known to modulate blood glucose. In our study the level of omentin showed a significant reduction with increasing doses of stevia prescription in diabetic rats. Esteghamati et al., in agreement 


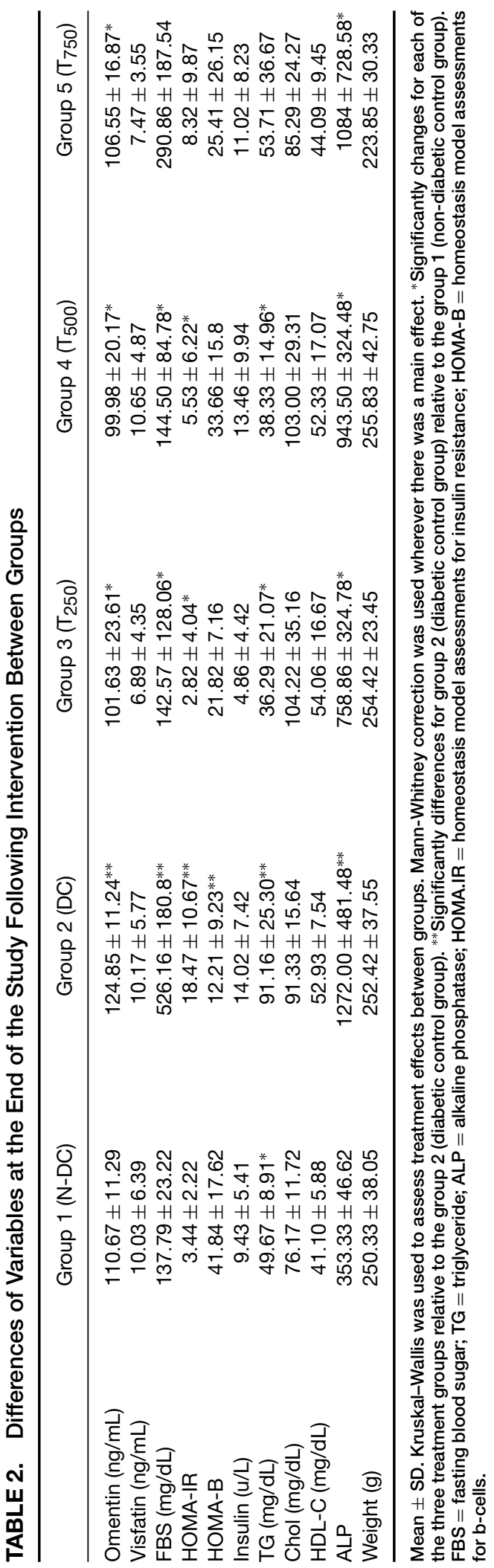


with our findings, reported a significant reduction in omentin level after administration of the herbal and artificial hypoglycemic medication (metformin and resiglitasone) in type 2 diabetic patients (Esteghamati et al., 2013). In our study and also in the research by Esteghamati et al., FBS similar to omentin decreased following consumption of the medication by the study subjects. In contrast, there are several reports showing an increase in the level of omentin following serum glucose reduction in diabetic individuals (Yan et al., 2011). To try to account for this discrepancy, we should address the mechanisms which are involved in modulating the blood glucose level by stevia compared to omentin. The biochemical pathways attributed to stevia in lowering blood glucose [suppression of hepatic glucose release, attenuation of glucagon secretion, and decrease of peripheral insulin resistance] are independent of the pathways attributed to omentin [3-kinase, Akt, or S160] (Saravanan, Vengatashbabu, \& Ramachandran, 2012; Shibata et al., 1995; Chen, Jeppesen, Nordentoft, \& Hermansen, 2007; Yang et al., 2006). If insulin sensitivity as well as regulation of blood glucose is restored via stevia dependent mechanisms, independently of omentin mechanisms, it could be concluded that the level of omentin is suppressed or at least attenuated after stevia prescription.

Therefore, stevia suppresses the level of serum omentin via amelioration of insulin resistance per se. In other words, stevia reduces omentin level indirectly via negative feedback. Additionally, declining serum omentin levels following stevia administration could be explained through the relationships between omentin and non-alcoholic fatty liver disease (NAFLD). There is a well-established association between increased omentin level and the incidence of NAFLD. It has been reported that the level of omentin is an independent predictor for disruption of microtubules and necrosis of hepatocyte in NAFLD (Yilmaz et al., 2011). On the other hand, the association between NAFLD and diabetes is very well established (Utzschneider \& Kahn, 2006). If NAFLD, which is a hepatic manifestation of metabolic syndrome and is characterized by insulin resistance (Utzschneider \& Kahn, 2006), is treated by stevia administration, it will regulate not only blood glucose but also omentin levels. It should also be noted that the effect of stevia on liver has been accompanied by protective properties (Saravanan et al., 2012). In summary it could be concluded that the ability of stevia to lower omentin levels might be primarily attributed to its hepatic protective functions, while acknowledging that other mechanisms are also involved.

In the current study the level of fasting plasma glucose decreased in those rats which consumed stevia in comparison with the control group. The hypoglycemic effect of stevia is recognized and could be found elsewhere (Gregersen, Jeppesen, Holst, \& Hermansen, 2004), although the mechanisms involved are not fully elucidated. Some reports have indicated that the hypoglycemic effect of stevia could attributed to the enhancement of insulin secretion (Jeppesen et al., 2000), the correction of liver gluconeogenic enzymes abnormalities (Saravanan et al., 2012), the suppression of glucagon secretion by the $\alpha$-cell of the pancreas (Shibata et al., 1995; Chen et al., 2007) and finally by augmentation of glucose utilization in peripheral tissues and muscles (Chen et al., 2005). Analysis of the data from the present study showed no significant changes in insulin level following stevia prescription. Accordingly HOMA-B did not changed throughout the study and analyzing the pancreatic 
biopsy samples of treated rats demonstrated no increase in B-cell in comparison to untreated groups (Figure 1). Sustained HOMA-B accompanied by a significant reduction in HOMA-IR, following stevia prescription, together lead us to assume that stevia decreases blood glucose via enhancing insulin binding capacity. In agreement with our findings, Chen et al. suggested stevioside is able to regulate blood glucose level by enhancing insulin utilization in insulin-deficient rats. He concluded that this property of stevia is due to decreased protein levels of phosphoenol pyruvate carboxykinase (PEPCK) and PEPCK mRNA which simultaneously slow down gluconeogenesis in rat liver (Chen et al., 2005). More studies are likely warranted to elucidate the ambiguities which have surrounded the mechanisms involved in the role of stevia in modulating blood glucose at the cellular levels.

Besides the hypoglycemic effects, our findings also point to a hypolipidemic role for stevia. The published sources about the impact of stevia in lipid profiles are scarce. In this study the TG level has decreased significantly after stevia administration. The hypo lipidemic property of stevia might be explained by interaction between stevia consumption and activation of peroxisome proliferators-activated receptors (PPARs). Recently a working model was developed, at the gene transcriptional level, which involves PPARs as a regulatory factor in lipogenesis process (Pegorier, May, \& Girard, 2004). Some studies indicated that PPARs could activate the expression of the lipoprotein lipase (LPL) and apo C-II genes as well as the hepatic uptake and esterification of free fatty acids, along with increasing mitochondrial free fatty acid oxidation (Fruchart \& Duriez, 2006; Auwerx, Schoonjans, Fruchart, \& Staels, 1996). Mueller et al. concluded that stevia can activate PPAR $\alpha$ and identified this property as a possible mechanism involved in the hypotriglyceridemic effect of stevia (Mueller, Beck, \& Jungbauer, 2011).

It should also be mentioned that the reduction of TG, FBS, ALK, and omentin did not appear in a dose dependent manner. With increasing dosage of stevia the beneficial impact was reduced. The U-shaped relationship between the stevia doses and the fasting blood glucose, the TG as well as the omentin levels in this study leads us to conclude that the impact of stevia on blood lipids glucose, liver enzyme, as well as on omentin has a saturation limit, beyond which further increase of stevia consumption has significant beneficial effect (Figures 2-4). It could therefore be concluded that here are therapeutic limits for this agent, beyond which not only are the beneficial characteristics eliminated but toxic implications appear. There are some reports indicating that the medium lethal dose (LD50) for stevia is more than $5 \mathrm{~g} / \mathrm{kg} / \mathrm{d}$, although lower doses have revealed no significant changes in the animal behavior, such as in alertness, motor activity, breathing, restlessness, diarrhea, convulsions, coma, and appearance. No death was also observed up to the dose of $5 \mathrm{~g} / \mathrm{kg}$ body weight (Kujur et al., 2010). The toxicity of herbal medicine has been always a subject of debate. The hepatic insult following herbal medicine treatment has been reported by several studies (Posadzki, Watson, \& Ernst, 2013; Nunes et al., 2007). In our study histopathology analysis of samples of liver biopsy showed no lesions at the dosage level applied in the study when compared to those of the control group (Figure 1). Shivanna et al. believed that stevia has renal and hepatic protective properties which are manifested by attenuation of malondialdehyde (MDA) and improvement of the antioxidant status of the liver. They believed that this characteristic is due to the antioxidant component of stevia (Shivanna, 


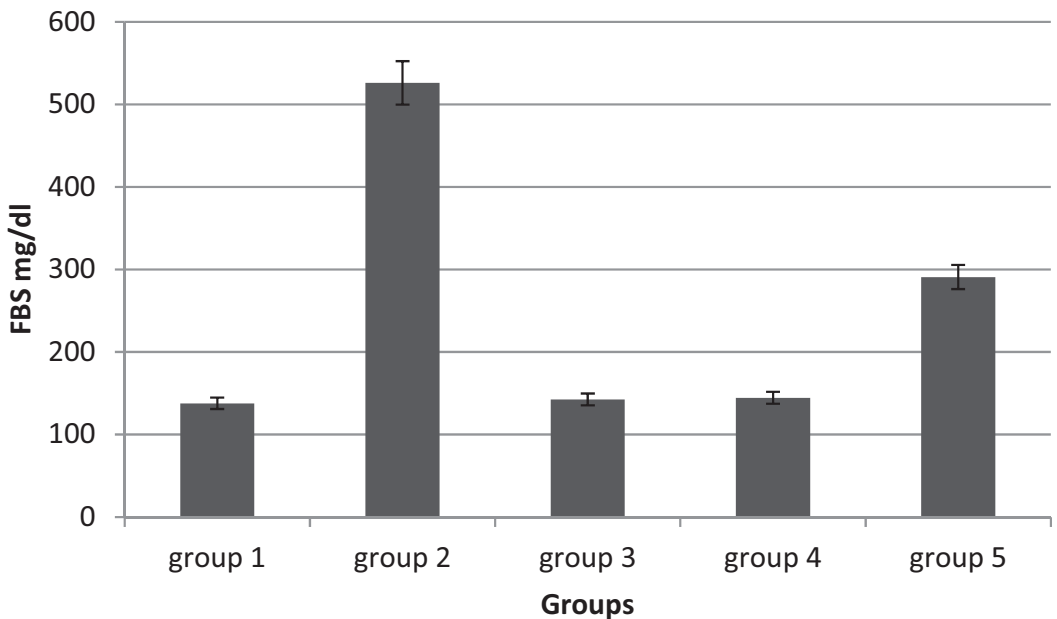

FIGURE 2. Effect of stevia on FBS. Prescription of stevia in doses of $250 \mathrm{mg} / \mathrm{kg} / \mathrm{d}$ in the group 3 and $500 \mathrm{mg} / \mathrm{kg} / \mathrm{d}$ in the group 4 decreased FBS significantly in respect to the group 2 (diabetic control group). No significant change in FBS was seen following prescription of stevia in doses of $750 \mathrm{mg} / \mathrm{kg} / \mathrm{d}$ a in group 5 in comparison with group $2(n=8$, mean \pm SD, $p<.05)$.

Naika, Khanum, \& Kaul, 2013). In the current study also a significant reduction in the hepatic ALP was found which confirms the hepatic protective role of stevia up to a dose of $250-500 \mathrm{mg} / \mathrm{kg} / \mathrm{d}$.

In the present study the visfatin level did not change following stevia prescription. Some studies have reported inconsistent and conflicting results regarding associations between visfatin and diabetes (Eriksson et al., 1989; Zhang et al., 2010).

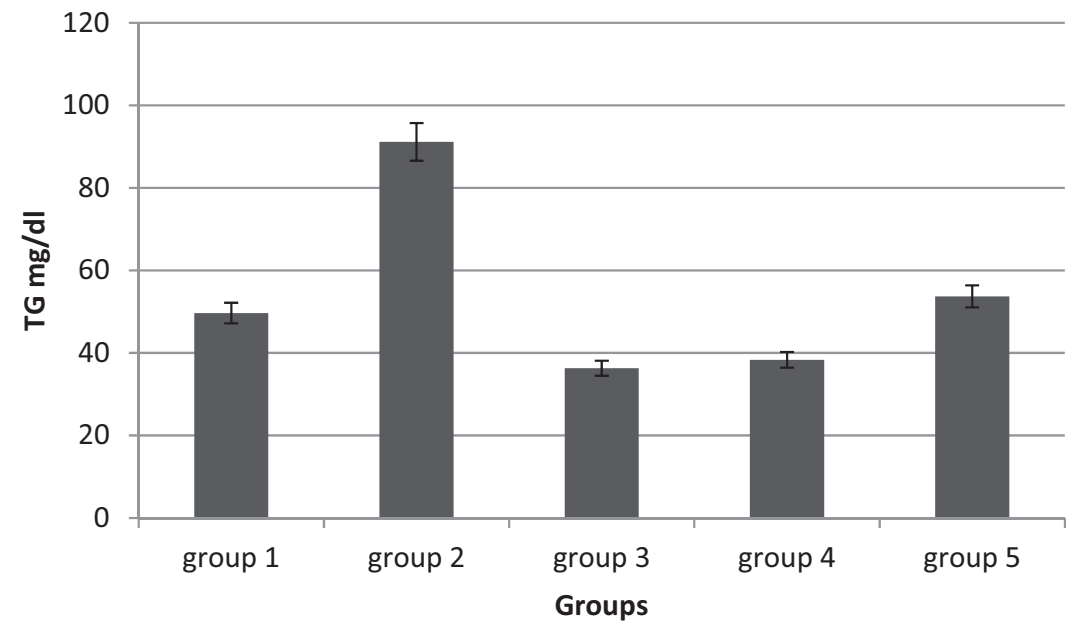

FIGURE 3. Effect of stevia on TG. Prescription of stevia in doses of $250 \mathrm{mg} / \mathrm{kg} / \mathrm{d}$ in group 3 and $500 \mathrm{mg} / \mathrm{kg} / \mathrm{d}$ in group 4 decreased TG significantly in respect of group 2 (diabetic control group). No significant change in FBS was seen following prescription of stevia in doses of $750 \mathrm{mg} / \mathrm{kg} / \mathrm{d}$ in group 5 in comparison with group $2(n=8$, mean $\pm \mathrm{SD}, p<.05)$. 


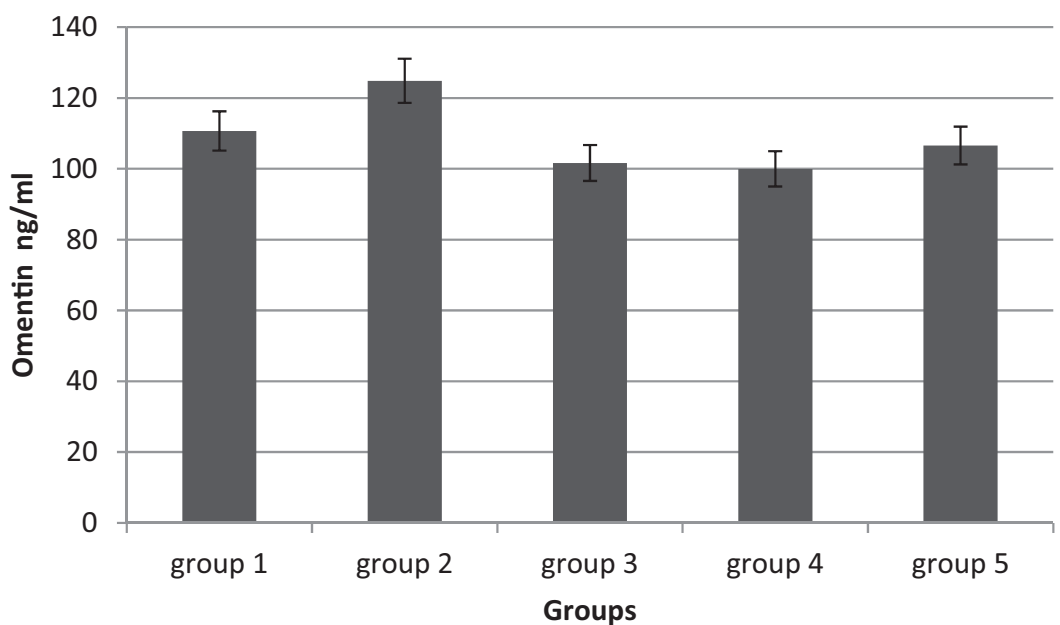

FIGURE 4. Effect of stevia on serum omentin level. Prescription of stevia in doses of $250 \mathrm{mg} / \mathrm{kg} / \mathrm{d}$ in group 3 and $500 \mathrm{mg} / \mathrm{kg} / \mathrm{d}$ in group 4 decreased omentin, significantly in comparison with group 2 (diabetic control group). No significant change in omentin was seen following prescription of stevia in doses of $750 \mathrm{mg} / \mathrm{kg} / \mathrm{d}$ in group 5 in comparison with group 2 ( $n=8$, mean \pm SD, $p<.05$ ).

The original work describing visfatin binding to IR has been withdrawn (Fukuhara et al., 2005).There are several reports that show significant correlation between plasma visfatin concentrations and the amount of visceral fat (Fukuhara et al., 2005; Haider et al., 2006). Han et al. found significant increase in visfatin level among obese compared to non-obese rats, which confirms the strong association between obesity and increased visfatin in animal models (Han, Zhang, Qin, \& Zhai, 2013). In our study the weight of the animals did not change throughout the study and this could be considered a potential reason for non-significant changes in visfatin level in the treated groups.

\section{CONCLUSION}

It is concluded that prescription of stevia in a dose of 250 and $500 \mathrm{mg} / \mathrm{d}$ p.o. decreases the omentin level indirectly via activating insulin sensitivity and lowering blood glucose in STZ-induced diabetic rats. It is worth mentioning that we did not evaluate the effects of ether extract and methanolic extract of stevia on the adipocytokines level in diabetic rats. A future study of this area would be worthwhile.

\section{ACKNOWLEDGMENTS}

This study was supported in part by the The Persian Gulf Tropical Medicine Research Center, Bushehr University of Medical Sciences, Bushehr, Iran (DP/8703277330,14/9/2010).

Declaration of interest: The authors report no conflict of interest. The authors alone are responsible for the content and writing of this paper. 


\section{ABOUT THE AUTHORS}

Samad Akbarzadeh and Afshar Bargahi, Department of Biochemistry, School of Medicine, Bushehr University of Medical Sciences, Bushehr, Iran. Fatemeh Eskandari, Hadis Tangestani, Somaieh Tangerami Bagherinejad, and Azam Sahrapoor, The student's committee research. School of Medicine, Bushehr University of Medical Sciences, Bushehr, Iran. Parviz Bazzi, Department of Anatomy, School of Medicine, Bushehr University of Medical Sciences, Bushehr, Iran. Adel Daneshi, The Persian Gulf Marine Biotechnology Research Center, Bushehr University of Medical Sciences, Bushehr, Iran. Ali Reza Rahbar, Department of Nutrition, The Persian Gulf Tropical Medicine Research Center, Bushehr University of Medical Sciences, Bushehr, Iran. William J O'Connor, The UCD School of Mechanical \& Materials Engineering, University College Dublin, Belfield Campus, Dublin 4, Ireland.

\section{REFERENCES}

Auwerx J, Schoonjans K, Fruchart JC, Staels B. Regulation of triglyceride metabolism by PPARs: fibrates and thiazolidinediones have distinct effects. J Atheroscler Thromb. 1996;3:81-89.

Bulcão C, Ferreira SR, Giuffrida FM, Ribeiro-Filho FF. The new adipose tissue and adipocytokines. Curr Diabetes Rev. 2006;2:19-28.

Chandran M, Phillips SA, Ciaraldi T, Henry RR. Adiponectin: more than just another fat cell hormone? Diabetes Care. 2003;26:2442-2450.

Chen TH, Chen SC, Chan P, Chu YL, Yang HY, Cheng JT. Mechanism of the hypoglycemic effect of stevioside, aglycoside of Stevia rebaudiana. Planta Med. 2005;71:108-113.

Chen J, Jeppesen PB, Nordentoft I, Hermansen K. Stevioside improves pancreatic? cell function during glucotoxicity via regulation of acetyl-CoA carboxylase. Am J Physiol Endocrinol Metab. 2007;292:1906-1916.

Eriksson J, Franssila-Kallunki A, Ekstrand A, Saloranta C, Widén E, Schalin C, Groop L. Early metabolic defects in persons at increased risk for non-insulin-dependent diabetes mellitus. $\mathrm{N}$ Engl J Med. 1989;321:337-343.

Esteghamati A, Noshad S, Rabizadeh S, Ghavami M, Zandieh A, Nakhjavani M. Comparative effects of metformin and pioglitazone on omentin and leptin concentrations in patients with newly diagnosed diabetes: a randomized clinical trial. Regul Pept. 2013;14:1-6. [Epub ahead of print]

Fallah-Hoseini H, Fakhrzadeh H, Larijani B, Shikhsamani A. Review of anti-diabetic medicinal plant used in traditional medicine. J Med Plant. 2006;5:1-8.

Fruchart JC, Duriez P. Mode of action of fibrates in the regulation of triglyceride and HDLcholesterol metabolism. Drugs Today (Barc). 2006;42(1):39-64.

Fukuhara A, Matsuda M, Nishizawa M, Segawa K, Tanaka M, Kishimoto K, Matsuki Y, Murakami M, Ichisaka T, Murakami H, Watanabe E, Takagi T, Akiyoshi M, Ohtsubo T, Kihara S, Yamashita S, Makishima M, Funahashi T, Yamanaka S, Hiramatsu R, Matsuzawa Y, Shimomura I. Visfatin: a protein secreted by visceral fat that mimics the effects of insulin. Science. 2005;307:426-430.

Gregersen S, Jeppesen PB, Holst JJ, Hermansen K. Antihyperglycemic effects of Stevioside in Type 2 diabetic subjects. Metabolism. 2004;53:73-76.

Han S, Zhang H, Qin L, Zhai C. Effect of dietary carbohydrate replaced with wild rice (Zizania latifolia (Griseb) Turcz) on insulin resistance in rats fed with high-fat/cholesterol diet. Nutrients. 2013;5:552-564.

Haider DG, Schindler K, Schaller G, Prager G, Wolzt M, Ludvik B. Increased plasma visfatin concentrations in morbidly obese subjects are reduced after gastric banding. J Clin Endocrinol Metab. 2006;91:1578-1581. 
Jeppesen PB, Gregersen S, Poulsen CR, Hermansen K. Stevioside acts directly on pancreatic beta cells to secrete insulin: actions independent of cylcic adenosine monophosphate and adenosine triphosphate sensitive potassium ion channel activity. Metabolism 2000;49:208-214.

Kujur RS, Singh V, Ram M, Yadava HN, Singh KK, Kumari S, Roy BK. Antidiabetic activity and phytochemical screening of crude extract of Stevia rebaudiana in alloxan-induced diabetic rats. Pharmacognosy Res. 2010;2:258-263.

Lailerd N, Saengsirisuwan V, Sloniger JA, Toskulkao C, Henriksen EJ. Effects of stevioside on glucose transport activity in insulin-sensitive and insulin-resistant rat skeletal muscle. Metabolism. 2004;53:101-107.

Matthews DR, Hosker JP, Rudenski AS, Naylor BA, Treacher DF, Turner RC. Homeostasis model assessment: insulin resistance and beta-cell function from fasting plasma glucose and insulin concentrations in man. Diabetologia. 1985;28:412-419.

Mueller M, Beck V, Jungbauer A. PPAR $\alpha$ activation by culinary herbs and spices. Planta Med. 2011;77:497-504.

Nunes AP, Ferreira-Machado SC, Nunes RM, Dantas FJ, De Mattos JC, Caldeira-de-Araújo A. Analysis of genotoxic potentiality of stevioside by comet assay. Food Chem Toxicol. 2007;45:662-666.

Pegorier JP, May CL \& Girard J. Control of gene expression by fatty acids. J Nutr. 2004;134:2444S-2449S.

Posadzki P, Watson LK, Ernst E. Adverse effects of herbal medicines: an overview of systematic reviews. Clin Med. 2013;13:7-12.

Saravanan R, Vengatashbabu K, Ramachandran V. Effect of Rebaudioside A, a diterpenoid on glucose homeostasis in STZ-induced diabetic rats. J Physiol Biochem. 2012;68:421-431.

Shibata H, Sawa Y, Oka T, Sonoke S, Kim KK, Yoshioka M. Steviol and steviol glycoside. Glucosyltransferase activities in S. rebaudiana Bertoni. Purification and partial characterization. Arch Biochem Biophys. 1995;321:390-396.

Shivanna N, Naika M, Khanum F, Kaul VK. Antioxidant, anti-diabetic and renal protective properties of Stevia rebaudiana. J Diabetes Complicat. 2013;27:103-113.

Soejarto DD, Kinghorn AD, Farnsworth NR. Potential sweetening agents of plant origin. III. Organoleptic evaluation of Stevia leaf herbarium samples for sweetness. J Nat Prod. 1982;45:590-599.

World Health Organization. Geneva: WHO; (2008). Diabetes, Fact sheet no. 312. [Last cited on 2010 May 23]. Available from: http://www.who.int/mediacentre/factsheets/ fs $312 /$ en/index.html

Yang RZ, Lee MJ, Hu H, et al. Identification of omentin as a novel depot-specific adipokine in human adipose tissue: possible role in modulating insulin action. Am J Physiol Endocrinol Metab. 2006;290:E1253-E1261.

Yan P, Li L, Yang M, Liu D, Liu H, Boden G, Yang G. Effects of the long-acting human glucagonlike peptide-1 analog liraglutide on plasma omentin-1 levels in patients with type 2 diabetes mellitus. Diabetes Res Clin Pract. 2011;92:368-374.

Yilmaz Y, Yonal O, Kurt R, Alahdab Y, Eren F, Ozdogan O, Celikel C, Imeryuz N, Kalayci C, Avsar E. Serum levels of omentin, chemerin and adipsin in patients with biopsy-proven nonalcoholic fatty liver disease. Scand J Gastroenterol. 2011;46:91-97.

Utzschneider KM, Kahn SE. Review: the role of insulin resistance in nonalcoholic fatty liver disease. J ClinEndocrinol Metab. 2006;91:4753-4761.

Zhang H, Xie H, Zhao Q, Xie GQ, Wu XP, Liao EY, Luo XH. Relationships between serum adiponectin, apelin, leptin, resistin, visfatin levels and bone mineral density, and bone biochemical markers in post-menopausal Chinese women. J Endocrinol Invest. 2010;33:707-711.

Zimmet P, Alberti KG, Shaw J. Global and societal implications of the diabetes epidemic. Nature. 2001;13:782-787. 